\title{
Identification of Relationships between Fingerprint Patterns and Gender in Koya, Kurdistan Region, Iraq.
}

\author{
Zaitoon A. Hamad ${ }^{1 *}$, Hemn R. Salih', Layla K. Ali ${ }^{2}$ \\ ${ }^{1}$ School of Medicine, Koya University, Koya, Kurdistan Region, Iraq, ${ }^{2}$ Department of Midwifery, Koya Technical Institute, Erbil Polytechnical \\ University, Koya, Kurdistan Region, Iraq
}

\section{${ }^{*}$ Corresponding author: \\ Zaitoon A. Hamad, \\ School of Medicine, Koya \\ University, Koya, Kurdistan \\ Region, Iraq. \\ E-mail: zaitoon.ahmed@ \\ koyauniversity.org}

Received: 12 July 2021

Accepted: 10 November 2021

Published: 30 December 2021

DOI

10.25156/pti.v11n2y2021.pp65-68

\section{A B S T R A C T}

According to this research probe the correlation between fingerprints and the gender for all 10 fingerprints. For this inquiry, 4939 samples were collected from 247 females and 247 male's ages between 7 and 13 years old. This is the first systematic research of its kind to check at ten fingerprints for people from Koya, Kurdistan region north of Iraq. As per the findings, gender identity is accurate for people with any of their ten fingerprints. After magnifying the obviously acquired photos, the four basic fingerprint structures were identified and registered: Arch, Radial loop, Ulner loop, and Whorl. Statistical analysis was performed using Chi-square analysis to determine the interaction and pattern between fingerprints and sex. The study show that, Archs (316), Ulnar loop (1450), Radial loop (1346), Whorl (1827). Out of which Arch's male $=(8.21)$, female $=(9.08)$, Ulner loop, male $=42.44$, female $=38.04$. Radial loop, male $=33.93$, female $=39.73$. Whorl, male $=51.55$, female $=48.44$ were noticed With respect to gender, these proportions of overall fingerprint patterns in both hands were significantly positive $\left(\chi^{2}=15.28\right.$, $P=0.00159$ ). $P<0.05$ indicates that the data are vital. Gender has no effect on fingerprint pattern distributions. As a consequence, there is a relationships between fingerprints and gender.

Keywords: Arches; Fingerprints; Gender; Loop; Radial; Ulner loop; Whorls

\section{INTRODUCTION}

Currently, the main popular applications of the dermatoglyphics pattern biometric method for detection have been considered, which has found a rising in public awareness (Rastogi and Pillai, 2010).

Harold Cummins, a Tulane University anatomist, invented the phrase "dermatoglyphics" to illustrate the analysis of epidermal ridges and the forms formed by them. The wordderm at glyph means "a skin carving” (Verbov, 1970), The finger prints are the pattern covering an area between the fingertip and the first joint of the finger, which remain the same from the cradle to the grave, this crucial fact makes the finger prints very important to identify the person far away from any doubts, for this reason, it is priceless for the law enforcement police when they used to identify a suspect and keep the innocent away from jail (Avery Robert, 2011), the science is ancient and old which has been used by the Chinses as a signature 1000 years ago.

The progress of a feature of human friction ridges occurs when the fetus is in the womb, during the $8^{\text {th }}$ week of gestation, and is completed by the $17^{\text {th }}$ week (Mirakovits, 2016). At the $14^{\text {th }}$ week, sweat gland ducts start to emerge or projected upwards from the bottom of the main friction ridges. After the $19^{\text {th }}$ week, the development of main ridges ends, and secondary ridges emerge in the form of layers existing between the primary ridges. Secondary ridges start to grow among all primary ridges by the $24^{\text {th }}$ week of pregnancy, and space was invaded by dermal papillae in the space between primary and secondary ridges, forming double rows (Singla).

Perspiration glands develop as a result of the forming of friction ridges. Then fingerprints display on the skin's surface, and the ridge system geometry remains unchanged for the remainder of one's life (Mirakovits, 2016).

Finger Signatures reveal specific characteristics because no two persons have the same shape, even though they have the same DNA profiles. Study of anatomy, classification, heredity, and racial difference, and he divided the distal phalanges of the fingertips into three classes: Arch, Loop, and Whorl. Was conducted by (Adebsi, 2009). 1 person in 64 billion the chance of two people having similar finger patterns (He and Chan, 2015).

"Carved works," distinguished the palmar and plantar skin which are friction ridges of the elevated epidermis. Dermatoglyphics refers to the arrangement of these patterns on the fingers (Bhat et al., 2014). Fingerprints are a strong individualism characteristic that serves as a valid criterion for identification (Kumar et al., 2009). Fingerprints 
are of paramount importance in forensic investigation. These are unique for an individual and remain unchanged throughout life (Basu, 1976).

There are three basic fingerprint forms in the Henry Classification: spiral, whorl, and arch (Henry, 1900) Signatures are widely regarded as the most effective method of identifying an individual. In court law, fingerprint proof is by far the most precise and effective level of logic.

The ridges formed during the prenatal period do not shift their orientation during an individual's life until the skin is decomposed, and two fingerprints of the same or different individuals are never similar, differing in patterns and ridge characteristics. Fingerprints are widely recognized as definitive proof in a court of law due to their one-of-a-kind (Gutiérrez-Redomero et al., 2013) distinguishing feature.

\section{MATERIALS AND METHODS}

\section{Material}

494 Students in elementary school in Koya city comprised 247 for males and female students ranging in age from 7 to 13 years. Students with permanent marks on their fingertips, any hand deformity, or an additional or bandaged finger were not permitted to participate in the research. Gender and age each student was advised to properly wash and dry his hands with soap and water.

Everyone's signatures are all over the place. The ten digits of an individual were then stamped with stamp pad ink on a white unglazed sheet. By not having the fingers to move, the print was safe from smudging. Henry's classification scheme. Fingerprint patterns were examined using a hand lens and categorized into circles, whorls, and arches.

\section{Methods and Data Analysis}

XLSTAT was used for statistical analysis (Addinsoft Version 2015.4.01.21575). The relationship and pattern between fingerprints and gender were calculated using Chi-square analysis. PP0.05 (at a 95\% trust level) was used to be analysis.

\section{RESULTS}

Loops (Ulnar + Radial) have been revealed to be of the most predominant kind of method in both genders followed by whorls. Whorls are prevailing in discovering of population, ulnar loop, and Radial loop then Arch. In addition, in this existing research paper the configurations and their subcategories were associated and then formulated which discloses a substantial variance for each configuration [Figure 1].
Among 494 specimens applied in this paper, $247(50 \%)$ male and 247 (50\%) female have been detected. Also, the dissemination of fingerprint configurations in terms of gender demonstrated the following outcomes, the result represents 4939 fingerprints for 494 samples a student has a wound in one finger, no clear fingerprint.

In Table 1 male had higher distribution with Whorl (51.55\%); Loop (Ulnar, 42.41, Radial (33.93) then Arch, (8.21) while females had higher distribution of whorl (48.44\%) and loops (Radial, 39.73, Ulnar, 38.04), (Arch 9.08). $\left(\chi^{2}=15.28, P=0.00159\right)$. This result agrees with the study (Joshi, 2018). There was a significant association with gender respectively.

\section{DISCUSSION}

In this article, it has been presented that one of the most advantages of applying fingerprint configurations as a sources of documentation is that it can be documented, protected, and saved when required during urgent actions. A loop has one and only with one delta pattern. There have been two main kinds of loops including radial loop and ulnar loop with respect to their locating and the movement of the edges (Verbov, 1970). Radial loop is so termed since the ridges flow or finalize in the path of radius bone of the forearm. The ulnar loop is so called for the reason that the edges flow or finalize in the path of ulnar bone of the forearm [Figure 2]. A whorl is considered by a circular approach having one or more ridges revolve around the core creation a whole circle. The whorl is that kind of configuration in which at minimum two deltas are present with a reserve in front of each (Avery Robert, 2011).

$\begin{aligned} & \text { Table 1: Distribution of fingerprint patterns in males and } \\
& \text { females }\end{aligned}$
\begin{tabular}{lcc}
\hline Fingerprint patterns & Male & Female \\
\hline Whorl & 51.55 & 48.44 \\
Ulnar Loop & 42.44 & 38.04 \\
Radial Loop & 33.93 & 39.73 \\
Arch & 8.21 & 9.08 \\
\hline
\end{tabular}

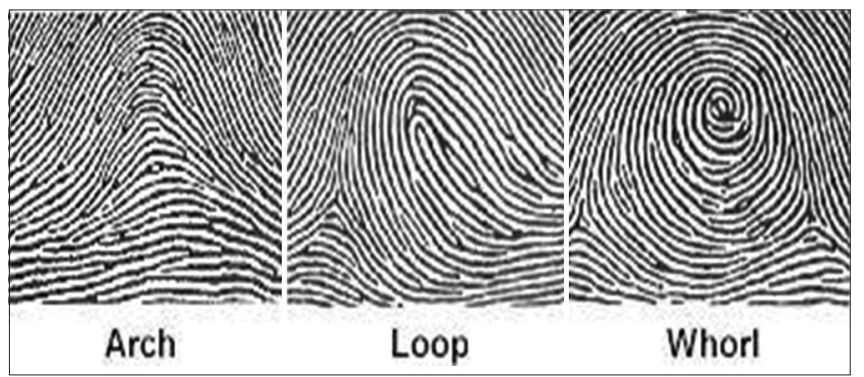

Figure 1: A unique hand finger print showing three distinct 


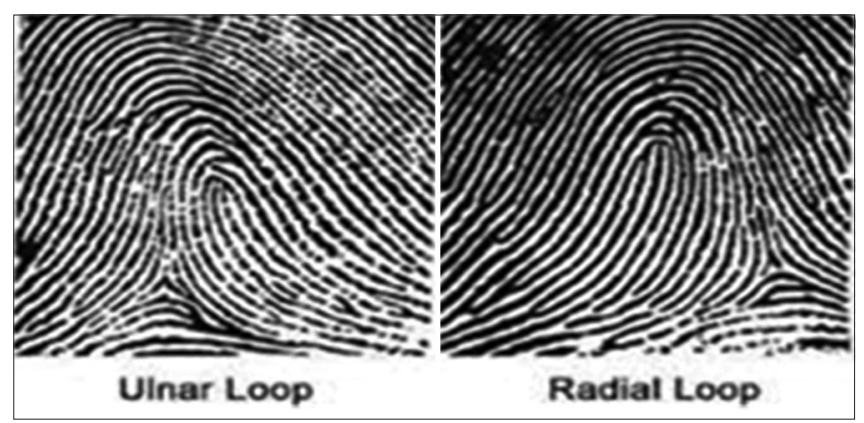

Figure 2: Types of Loop (UInar loop and Radial loop)

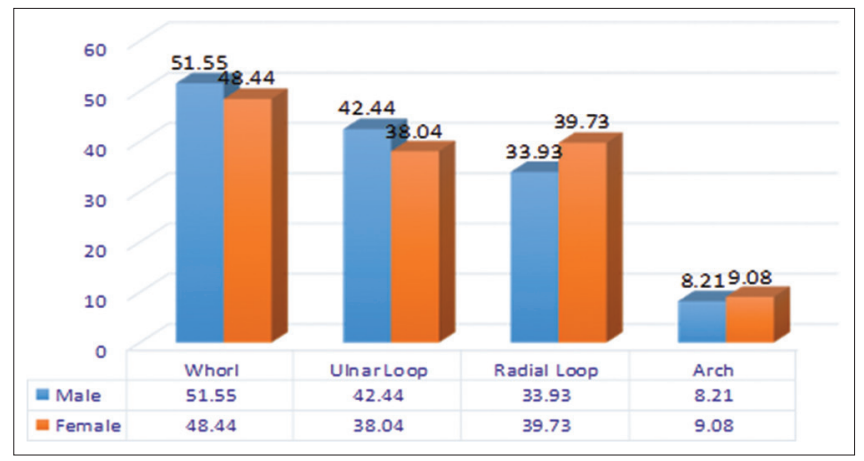

Figure 3: Graph showing relation between fingerprint pattern and gender

Their study reported that distributions of fingerprint Whorls were (51.55) in male and more than in female (48.44). Loops in male (76.34) but in female (77.77) Arch, (8.21) in female (9.08), Ulner loop in male (42.44) and Radial loop is (33.93) but Radial loop in female (39.73) more than Ulner loop (38.04) [Figure 3]. The alterations between gender and fingerprint configurations were in the frequency of Loops and Arches; which they specified that Arches have been high in females, whereas Whorls have been presented to be high in males. Moreover, loops in females higher than in males. The result of this study is agree with (Mohsin and Hasan, 2020; Bhavana et al., 2013).

Gender alteration in the distribution and relationship between fingerprint categories and gender, there have been disparities in the percentage and distribution of fingerprint kinds between genders. There have been more Loops followed by Spirals, and the smallest stayed Arches in both males and females, though, Loops were prevalent in females and male. The current investigation is compared with the other. According to a recent study conducted by (Nithin et al., 2009) who investigates the delivery of fingerprint methods in South Indians of Mysore detected and documented the most prevalent of Ulnar loops, followed by whorl, then combined, then arch configuration and similar research was perceived in this study.

\section{CONCLUSION}

This study has outlined that there is a substantial alterations between gender and fingerprint, the spreading of fingerprint methods are independent of gender of an individual. Consequently, it possibly will not be completely incorrect to propose that there is no association between fingerprints and gender; hence there might not be inherited relation between them. Moreover, the dispersal of fingerprint methods and their sub-categories was completed from which it was determined that loop configurations are predominant and principal category in both genders and Arch pattern are the smallest prevailing sorts. The statistics and analytical data were summarized in tabular method and the chart was sketched to display the spreading of fingerprint forms among both genders. The subdivision of loop in other words, was deliberated as the most collective fingerprint form in both genders. Based on the results, the paper has confirmed that there has been a disproportional relationship between Ulnar loop and radial loop in which the former is more than in male but the latter loop is more predominant in female as compared to male. Furthermore, composite and tented arch are confirmed to be the least common types of fingerprints. This study improves the inevitability of fingerprints as a dependable instrument for creating human characteristics and identification personality.

\section{ACKNOWLEDGMENT}

We are extremely thankful to the (Management of Nawroz primary School for boys and girls) for their active participation.

\section{REFFERENCES}

Adebsi, S. 2009. Fingerprint studies-the recent challenges and advancements: A literary view. Internet J. Biol. Anthropol. 2(2): 1-9.

Avery Robert, D. 2011. The Scientific Study of Finger Prints and How it is Used in Society.

Basu, A. 1976. Digital dermatoglyphics of three caste groups of Mysore. Am. J. Phys. Anthropol. 45(3): 437-441.

Bhat, G. M., M. A. Mukhdoomi, B. A. Shah and M. S. Ittoo. 2014. Dermatoglyphics: In health and disease-a review. Int. J. Res. Med. Sci. 2(1): 31-37.

Bhavana, D., J. Ruchi, T. Prakash and J. L. Kalyan. 2013. Study of fingerprint patterns in relationship with blood group and gender-a statistical review. Arches. 1(1): 15-17.

Gutiérrez-Redomero, E., A. Sánchez-Andrés, N. Rivaldería, V. Alonso-Rodríguez, J. E. Dipierri and L. M. Martín. 2013. A comparative study of topological and sex differences in fingerprint ridge density in Argentinian and Spanish population samples. J. Forensic Leg. Med. 20(5): 419-429.

He, S. and S. H. G. Chan. 2015. Wi-Fi fingerprint-based indoor positioning: Recent advances and comparisons. IEEE Commu. 
Surv. Tutor. 18(1): 466-490.

Henry, E. R. 1900. Classification and Uses of Fingerprints. George Rutledge and Sons, Limited, London. p54.

Joshi, S., D. Garg, P. Bajaj and V. Jindal. 2016. Efficacy of fingerprint to determine gender and blood group. J. Dent. Oral. Care Med. 2(1): 103.

Kumar, L., S. S. Agarwal, K. H. Chavali and S. C. Mestri. 2009. Homicide by organophosphorus compound poisoning. Med. Sci. Law. 49(2): 136-138.

Mirakovits, K. 2016. Forensic Science: The Basics. CRC Press, United States.
Mohsin, T. S. and H. S. Hasan. 2020. The relation between left thumb fingerprint types with blood groups and gender among students of Al-Kindy College of Medicine. Prensa Med Argent. 106: 1-3.

Nithin, M. D., B. M. Balaraj, B. Manjunatha and S. C. Mestri. 2009. Study of fingerprint classification and their gender distribution among South Indian population. J. Forensic Leg. Med. 16(8): 460-463.

Rastogi, P. and K. R. Pillai. 2010. A study of fingerprints in relation to gender and blood group. J. Indian Acad. Forensic Med. 32(1): 11-14.

Verbov, J. 1970. Clinical significance and genetics of epidermal ridges-a review of dermatoglyphics. J. Invest. Dermatol. 54(4): 261-271. 